\title{
Formulation of Insulin Self Nanoemulsifying Drug Delivery System and Its In Vitro-In Vivo Study
}

\begin{abstract}
Lina winarti ${ }^{12 *}$, Suwaldi ${ }^{3}$, Ronny Martien ${ }^{3}$, Lukman Hakim ${ }^{4}$
1Postgraduate Programme, Faculty of Pharmacy, Universitas Gadjah Mada, Yogyakarta 55281, Indonesia; 2Department of Pharmaceutics, Faculty of Pharmacy, University of Jember, Jember 68121, Indonesia; 3Dept of Pharmaceutical Technology Faculty of Pharmacy, Universitas Gadjah Mada, Yogyakarta 55281, Indonesia. 4Dept of Pharmacology and Clinical Pharmacy, Faculty of Pharmacy, Universitas Gadjah Mada, Yogyakarta 55281, Indonesia.

Submitted: 02-04-2018 Revised: 14-05-2018 Accepted: $12-06-2018$

*Corresponding author Lina Winarni

Email:

lina.winarti@unej.ac.id
\end{abstract}

\section{INTRODUCTION}

Oral insulin has not been commercially available due to the low bioavailability of insulin in the gastrointestinal tract (Sadrzadeh et al., 2007). The enzymatic degradation in the gastrointestinal tract and low permeability of intestinal membrane result in the low bioavailability of per-oral insulin (Almaeda and Souto, 2007).

The approach for oral protein formulation is the use of specific excipients such as absorption enhancers, enzyme inhibitors, mucoadhesive polymers, and other formulations enabling protein protection against extreme environment in the gastrointestinal (Park et al., 2011) like encapsulation of various delivery system including nanoparticles (Sonaje et al.,
2009; Nair et al., 2017; Kunasekaran and Krishnamoorthy, 2015), microemulsion (Sharma et al., 2010), self-nanoemulsifying drug delivery system (SNEDDS) (Ma et al., 2006; Li et al., 2012; Zhang et al., 2012; Sakloetsakun et al., 2013; Rao et al., 2008; Rachmawati et al., 2010), liposome (Wu et al., 2011), and mixed with an aqueous extract obtained from Desmodium Gangeticum roots (Kurian et al., 2010). Among those preparations, SNEDDS is potential to be developed as a protein delivery system. SNEDDS is a homogenous complex system which consists of oil, surfactant, co-surfactant, and co-solvent (Patel et al., 2013). The system is also named as emulsion pre-concentrate. By light agitation in aqueous media leads to the formation of translucent emulsion (Mishra et al., 
2014). In some studies, SNEDDS is proven to be superior rather than the lipid solution due to the surfactant availability in its formulation; it is homogenous, the drug absorption is more consistent, it protects drugs against gastrointestinal environment, the bioavailability gets increased, and the efficiency of absorption becomes higher (Kaur and Harikumar, 2013).

SNEDDS has been applied to deliver hydrophobic drugs such as coenzyme Q10 (Khattab et al., 2016), halofantrine (Michaelsen et al., 2013), simvastatin (Thomas et al., 2013), vitamin E-rutin (Khan et al., 2015), and cyclosporine A (Jain et al., 2015). Some studies reveal that SNEDDS is also used for protein and peptide drug such as BSA (Rachmawati et al., 2002; Winarti et al., 2016a; Winarti et al., 2016b), B-lactamase (Rao et al., 2008), Insulin (Ma et al., 2006; Li et al., 2012; Zhang et al., 2012, Sakloetsakun et al., 2013).

SNEDDS insulin prepared by previous researchers (Li et al., 2012; Zhang et al., 2012) using phospholipid to produce insulin phospholipid complex. The resulted insulinphospholipid complex improved the insulin solubility in oil. Other reseracher prepared SNEDDS for mucus permeating by initially processing the insulin through hidrophobic ion pair of insulin/dimyristoyl phosphatidylglycerol method to improve the insulin solubility in the system and prevent from burst release (Karamanidou et al., 2015). This formulation of SNEDDS insulin resulted in higher in vitro and in vivo permeability.

In this study, insulin was dissolved in glycerol and incorporated in optimum SNEDDS template optimized using D-optimal mixture design. The optimum SNEDDS template loaded insulin was characterized and evaluated for in vitro diffussion study and in vivo study. The study using rat was approved by the Ethics Commission of Integrated Reserach and Testing Laboratory, Universitas Gadjah Mada no. 00077/04/LPPT/X/2016.

The approach applied in this research is said to be able to succeed the generation of effective insulin delivery system. In addition, this study suggests interesting possibilities for other proteins formulated by SNEDDS. Studies using insulin as active ingredient that apply this approach have not been established. Therefore, this study aims to develop optimum SNEDDS template for potential oral insulin delivery.

\section{MATERIAL AND METHODS}

This study used Bovine Insulin from Beijing Top Science Biotechnology Co., Ltd., Miglyol 812N from CREMER OLEO GmbH \& Co.KG, Tween 80, Span 20, Span 85 from Sigma Aldrich, Chremophor EL 40 was a gift from Shanghai Terppon China, propylene glycol from Bratachem Indonesia, glycerol from Merck, Bradford reagen kit from BioRad, Female Wistar rats obtained from Pharmacology and Pharmacy Clinic Laboratory of Pharmacy Faculty University of Gadjah Mada, and ELISA Bovine Insulin Kit from ALPCO USA.

\section{Compatibility study of oils-surfactants- co-surfactant mixture}

Various oil components consist of Miglyol $812 \mathrm{~N}$, Span 85, and oleic acid, surfactants (Tween 80, Tween 20, and Cremophor EL 40), and co-surfactants (Span 20, and propylene glycol) used for SNEDDS component. The compatibility of oil: surfactants: co-surfactants (1:1:1, 1:2:1, 1:3:1, 1:4:1, 1:5:1, 1:6:1, 1:7:1, 1:8:1, 2:1:1, 2:2:1, 2:3:1, 2:4:1, 2:5:1, 2:6:1, 2:7:1, 2:8:1, $3: 1: 1,3: 2: 1,3: 3: 1,3: 4: 1,3: 5: 1,3: 6: 1,3: 7: 1,3: 8: 1)$ was visually observed for three days. The mixtures of the components with the largest miscibility area and with the highest emulsion transparency produced at a short emulsification time were used to construct the ternary phase diagram and to optimize the composition of SNEDDS templates.

\section{Construction of pseudoternary phase diagram}

Based on the compatibility study, the mixtures of the components that fulfilled the evaluation criteria were used to construct the pseudoternary phase diagram.

\section{Optimization of SNEDDS template with D-optimal}

The optimization using D-optimal mixture design was performed on three independent variables which are oil (Myglyol 81) 10-25\%, surfactant (Tween 80) 50-80\%, and cosurfactant (propylene glycol) $10-25 \%$, and it was also on two dependent variables which are $\%$ transmittance (Y1) and emulsification time (Y2). 


\section{Optimum formula verification}

The optimum formula verification was done to determine the suitability of the predicted value with the value of the observation (actual value).

\section{Preparation of insulin SNEDDS}

Insulin was dissolved in glycerin and was stirred in the mixture of surfactant (Tween 80), co-surfactant (propylene glycol) and Myglyol $812 N$. Each gram of SNEDDS template was added with $100 \mu \mathrm{L}$ of glycerin containing insulin.

\section{Determination of emulsion droplet size and zeta potential \\ SNEDDS Insulin was added with} distilled water $(1: 1000)$ in a test tube. The particle size was measured and the polydispersity index (PDI) of the formulated nanoemulsion was analyzed using DelsaTM Nano Beckman Coulter.

\section{Evaluation of emulsification time}

SNEDDS insulin of $250.0 \mu \mathrm{L}$ was quickly dripped into a baker glass using $250.0 \mathrm{~mL}$ distilled water, simulated gastric fluid PH 1.2 and phosphate buffer $\mathrm{pH} 6.8$ at $37 \pm 0.5^{\circ} \mathrm{C}$. The medium was stirred at a speed of $100 \mathrm{rpm}$ (Weerapol et al., 2014). The time to form nanoemulsion was recorded as emulsification time.

\section{Transmittance percentage}

SNEDDS insulin of $100 \mu \mathrm{L}$ was added to a vial containing $10 \mathrm{~mL}$ and $100 \mathrm{~mL}$ double distilled water, Simulated Gastric Fluids pH 1.2, and phosphate buffer $\mathrm{pH} 6.8$ at the room temperature, stirred for a minute and measured for its transmittance using SpectroVis at $\lambda 650$ nm (Reddy and Sowjanya, 2015).

\section{Procedure of in vitro difussion study (Ussing Chamber)}

The diffusion study was conducted using Ussing Chamber and intestine of male Wistar rats put on a chip chamber. SNEDDS insulin $(1 \mathrm{~mL})$ was dispersed in AIF (Artificial Intestinal Fluids) at $\mathrm{pH} 6.8$ and put into the mucosal compartment. The non-SNEDDS insulin was used as the comparator. Phosphate buffer saline $\mathrm{pH} 7.4$ was added into serosal compartment. The Ussing chamber was set on the water bath at $37 \pm 0.5^{\circ} \mathrm{C}$. The oxygen was distributed at the speed of \pm 100 bubbles per minute to keep the membrane function. Sampling technique was performed by taking $1 \mathrm{~mL}$ solution of the serosal at the $0^{\text {th }}, 15^{\text {th }}, 30^{\text {th }}, 45^{\text {th }}, 60^{\text {th }}, 90^{\text {th }}, 120^{\text {th }}, 180^{\text {th }}$, $240^{\text {th }}$, and $300^{\text {th }}$ minute. To keep the sinking condition, the solution was changed to $1 \mathrm{~mL}$ of serosal media. The sample obtained was centrifuged at a speed of $3.000 \mathrm{rpm}$ for $5 \mathrm{~min}$ to eliminate intestinal debris. The content detection was performed with visible spectrophotometer through validated micro Bradford Assay. This method was carried out by reacted $160 \mu \mathrm{L}$ sample solution with $40 \mu \mathrm{L}$ Bradford Reagent, then allowed to stand for at least $5 \mathrm{~min}$, and no more than $1 \mathrm{~h}$. Absorbance was measured at maximum wavelengths against blanks.

\section{In vivo pharmacokinetic study Experimental animal}

The experimental animal used in the in vivo test was treated based on the approved procedure by the Ethics Commission of LPPT UGM no. 00077/04/LPPT/X/2016. The animals used are healthy 1.5-2-month-old female Wistar rats (150-250g). The rats were kept in light cage for $12 \mathrm{~h}$ and in dark cage for 12 $\mathrm{h}$, and were given standard diet and sufficient water access (ad libitum).

\section{Induction of diabetes}

The induction of diabetes in rats were performed through the injection of Intraperitoneal Streptozotocin $(48 \mathrm{mg} / \mathrm{kg}$ ) in $10 \mathrm{mM}$ citrate buffer $(\mathrm{pH} 4.5)$ of rats fasted for $14 \mathrm{~h}$ with water access (ad libitum). The rats for the following test were selected based on the glucose level $>250 \mathrm{mg} / \mathrm{dL}$ after five days of streptozotocin induction.

\section{Treatment of experimental animals}

The study for blood insulin profile was conducted by randomly dividing 28 rats into seven groups; each group consists of 4 rats. The experimental groups of the study are: Grup I was given $5.0 \mathrm{~mL} / 200 \mathrm{~g}$ blank SNEDDS (oral); Grup II was given 43.39IU/KgBW SNEDDS Insulin (1mL oral); Grup III was given 108.47IU/KgBW SNEDDS insulin $(2.5 \mathrm{~mL}$ oral); Grup IV was given $216.94 \mathrm{IU} / \mathrm{KgBW}$ SNEDDS insulin ( $5 \mathrm{~mL}$ oral), Grup $\mathrm{V}$ was given 5.0 mL/200gr PBS pH 7.4 (oral); Grup VI was 
given $200 \mathrm{IU} / \mathrm{KgBW}$ non-SNEDDS insulin (oral), and Grup VII was given $10 \mathrm{IU} / \mathrm{KgBW}$ subcutaneous insulin.

\section{Sample Analysis}

The blood sample $(0.5 \mathrm{~mL})$ was obtained from the eye orbital sinus at the $0^{\text {th }}, 15^{\text {th }}, 30^{\text {th }}$, $45^{\text {th }}, 60^{\text {th }}, 90^{\text {th }}, 120^{\text {th }}, 240^{\text {th }}, 480^{\text {th }}$, and $600^{\text {th }}$ minute. The serum insulin concentration $(25 \mu \mathrm{L})$ was measured using Bovine Insulin ELISA Kit.

\section{Statistical Analysis}

The differences of each treatment group were statistically analyzed with $\mathrm{p}<0.05$ indicating significantly different.

\section{RESULTS AND DISCUSSION Development of SNEDDS templates}

The component screened for SNEDDS templates shows that Miglyol 812N: Tween 80: propylene glycol produced the mixtures fulfilling the designed criteria. Oleic acid and Span 85 tend to form less transparent emulsion than Miglyol 812 N. Mygliol 812 is medium chain triglyceride with the HLB value 15.36 (Kawakami et al., 2002), while the HLB of Span 85 is 1.8 and HLB of oleic acid is 1.0. It was reported that lipid with higher polarity is easier to form nano-emulsion (Hong et al., 2006). Oil that has long hydrocarbon chain like oleic acid and Span 85 (C18) is difficult to form nano-emulsion; Miglyol $812 \mathrm{~N}$ has such medium-long hydrocarbon chain that is emulsified easily (Anton and Vandamme, 2009; Sadurní et al., 2005). Span 85 is a sorbitan trioleate, a long hydrocarbon chain, resulting in higher viscosity (200-300mpas) than Miglyol 812 has (27-33mpas) and oleic acid (25.6mpas); Span 85 has less spontaneous nanoemulsifying and tends to from bigger-sized droplets.

Tween 80 is able to form nano-emulsion with Miglyol 812 due to its higher HLB value than of Cremophor EL 40; although HLB of Tween 80 is lower than of Tween 20, it can form better nano-emulsion than Tween 20 (Chinwong et al., 2012; Macedo et al., 2006).

\section{Phase Diagram of SNEDDS Formulation}

Pseudoternary phase diagram was constructed to estimate the concentration in which SNEDDS templates can form nanoemulsion when added to water. The diagram consists of Miglyol 812N: Tween 80: propylene glycol (Figure 1). Red squares showed the nanoemulsion.

\section{Optimization of SNEDDS template with D-optimal \\ Response of \% transmittance}

The $\%$ transmittance is one of SNEDDS characteristics that needs to be evaluated for its use to predict the size of emulsion droplets (Nasr et al., 2016). The equation for $\%$ transmittance using D-optimal Design (pseudo components) is as follow:

$\mathrm{Y} 1=-8.43 * \mathrm{~A}+9.8 * \mathrm{~B}+8.89 * \mathrm{C}+28.79 * \mathrm{~A} * \mathrm{~B}+2.07$ $* \mathrm{~A} * \mathrm{C}+2.67 * \mathrm{~B} * \mathrm{C}$.

Remarks: $\mathrm{Y} 1=\sqrt{ }$ transmittance; $\mathrm{A}=$ Miglyol $812 \mathrm{~N}$ composition; B $=$ Surfactant (Tween 80) composition; $\mathrm{C}=$ Co-surfactant (propylene glycol) composition

Based on the equation 1, oil reduced the $\%$ transmittance due to the improving amount of oil composition leading to the increased droplet size. It results in the decreased value of $\%$ transmittance (Desmukh and Kulkarni, 2014). In contrast, surfactants increase the value of $\%$ transmittance as they will be absorbed on the oil surface so fast that the oil changes into smallsized droplets in continuous phase. Cosurfactants support surfactants to reduce the surface tension into negative value and to modulate the drop size to nanometer by decreasing the interfacial bending stress and increasing the flexibility of an interfacial film (Nasr et al., 2016). Consequently, due to the synergic function, the increased amount of cosurfactants results in the increased value of $\%$ transmittance.

The oil-surfactant interaction has the biggest influence on $\%$ transmittance for the viscosity of oil-surfactant combination lower than of surfactant; it results in easier penetration of water in the nano-emulsion formation process (Ittiqo et al., 2016).

\section{Response of emulsification time}

Emulsification time is essential parameter in evaluating the efficiency of self nanoemulsion formation (Basalious et al., 2010; Costa et al., 2012). 

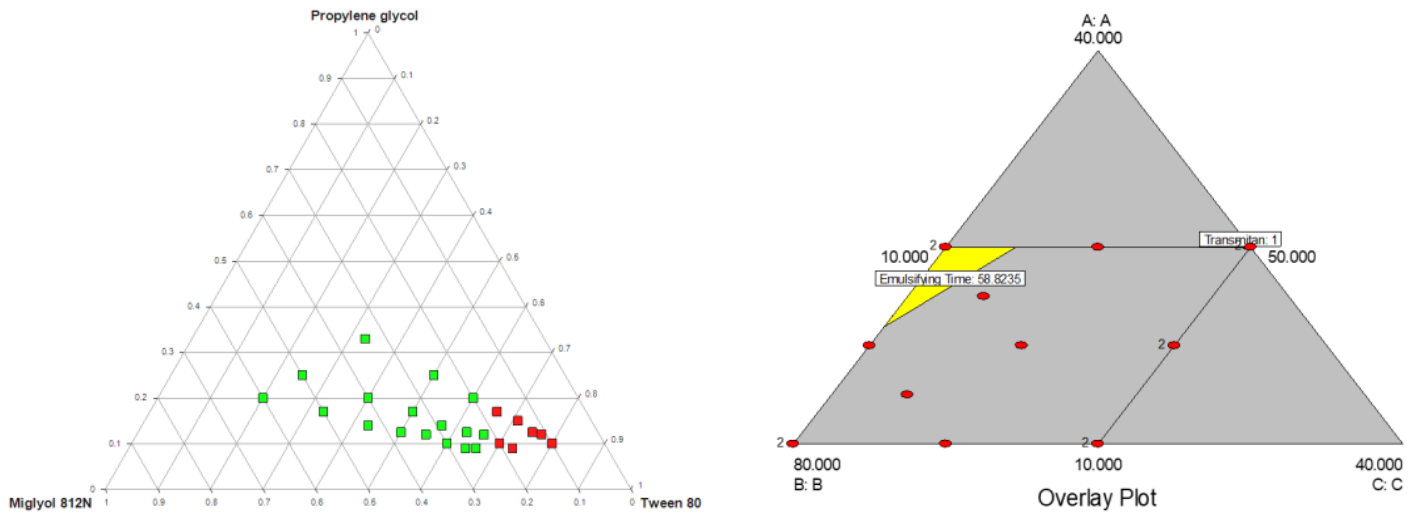

Figure 1. Pseudoternary phase diagram of SNEDDS template consist of Miglyol 812N:Tween Figure 2. Overlay plot of $\%$ transmitan and 80:Propylene glycol emulsification time

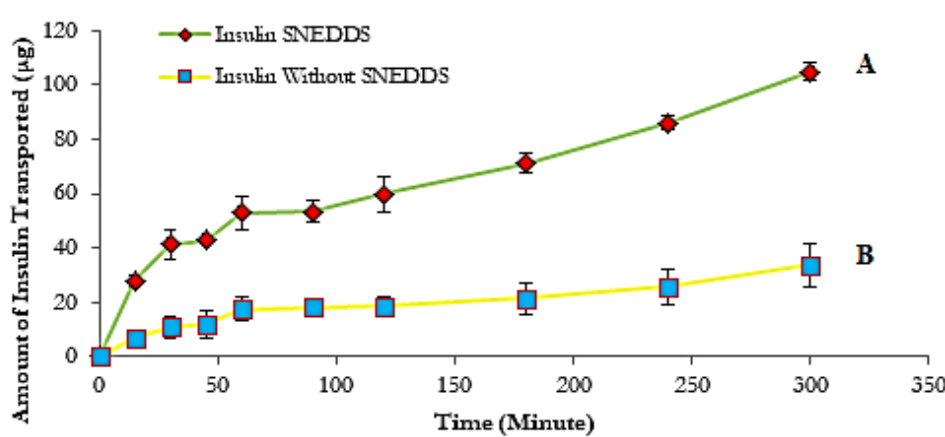

Figure 3. Amount of insulin transported across rat gut in vitro for $5 \mathrm{~h}$ (average \pm sd) (a) insulin SNEDDS, (b) insulin non SNEDDS

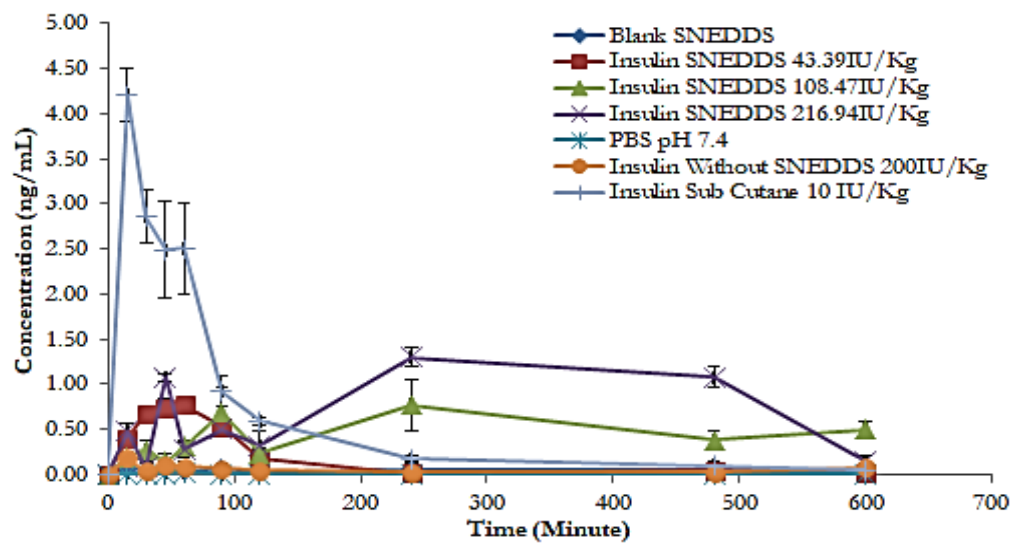

Figure 4. Profile of serum insulin concentration (Average \pm SEM, $n=4$ ) 
Table I. Pharmacokinetic parameters after oral administration

\begin{tabular}{lcccc}
\hline Treatment & $\begin{array}{c}\text { Cmax } \\
(\mathbf{n g} / \mathbf{m L})\end{array}$ & $\begin{array}{c}\text { Tmax } \\
(\text { min) }\end{array}$ & $\begin{array}{c}\mathbf{A U C}_{\mathbf{0 - 1 0}} \\
\text { (min.ng.mL-1) }\end{array}$ & F \\
\hline Insulin non SNEDDS 200IU/Kg BB & $0.52 \pm 0.51$ & $15-60$ & $27.34 \pm 10.00$ & $0.004 \pm 0.003$ \\
Insulin SNEDDS 43.39IU/Kg BB & $0.82 \pm 0.19$ & $45-60$ & $85.86 \pm 16.10$ & $0.062 \pm 0.024$ \\
Insulin SNEDDS 108.47IU/Kg BB & $0.77 \pm 0.17$ & 240 & $293.23 \pm 42.76$ & $0.084 \pm 0.027$ \\
Insulin SNEDDS 216.94 IU/Kg BB & $1.31 \pm 0.19$ & 240 & $506.75 \pm 32.75$ & $0.073 \pm 0.008$ \\
Insulin Sub Cutane 10IU/Kg BB & $4.21 \pm 0.57$ & 15 & $324.60 \pm 26.33$ & 1 \\
\hline
\end{tabular}

The obtained equation of D-optimal Design (pseudo components) for response of emulsification time is as follow:

$\mathrm{Y} 2=-0.029 * \mathrm{~A}+0.036 * \mathrm{~B}+0.15 * \mathrm{C}$

Remarks: $\mathrm{Y} 2=1 /$ Emulsification time; $\mathrm{A}=$ Miglyol $812 \mathrm{~N}$ composition; $\mathrm{B}=$ Surfactant $($ Tween 80$)$ composition; $\mathrm{C}=$ Co-surfactant (propylene glycol)

Oil increase the emulsification time while both surfactant and co-surfactant decreases the emulsification time. Oil prolong the emulsification time due to different phase of oil and water that results in high surface tension prohibiting the water penetration in forming nano-emulsion spontaneously (Ruan et al., 2010).

The optimization result shows the optimal ratio of Miglyol 812: Tween 80: propylene glycol is 10:65:25 $(\% \mathrm{w} / \mathrm{w})$ with the desirability of 0.97 . Figure 2 shows mixed overlay plots resulted by two responses.

\section{Verification of optimal formula}

The verification result showed no significant difference between the prediction value and observation value of $\mathrm{Y} 1$ and $\mathrm{Y} 2$ with $p>0.05$ therefore that the prediction value experimentally fits with the observation value.

\section{Particle size and zeta potential}

The analysis result of particle size indicated that the droplet size of insulin nanoemulsion is $12.0 \pm 1.7 \mathrm{~nm}$ with narrow distribution size (polydispersity index $=0.243$ ) and the zeta potential is $+0.16 \mathrm{mV}$.

Visual observation of emulsification time Emulsification time of SNEDDS insulin occurs fast in three media, with emulsification time $<60$ s, it belongs to grade A for less than one-minute emulsification time, and it has transparent or clear bluish appearance (Kaur et al., 2003).

\section{The \% transmittance}

The $\%$ transmittance of SNEDDS insulin $(>90 \%)$ indicates transparency formula or ability to form nano-emulsion in the used media.

\section{Diffusion test with ussing chamber}

Validation process to determines the level of insulin transported during diffusion study has been successfully carried out according to $\mathrm{ICH}$ Guideline Q2 (R1). Validation parameters include selectivity, linearity, LOD, LOQ, accuracy, and precision. Microbradford assay used in this study was selective, linear, accurate and precise. LOD and LOQ were obtained $0.49 \mu \mathrm{g} / \mathrm{mL}$ and $1.64 \mu \mathrm{g} / \mathrm{mL}$. The result of diffusion test with Ussing Chamber shows that the amount of transported insulin of SNEDDS preparation $(32.45 \pm 2.03 \%)$ is significantly different $(\mathrm{p}=0.001)$ from non-SNEDDS insulin $(10.44 \pm 5.04 \%)$ (Figure 3). The test result reveals that SNEDDS significantly influences the increase of flux and amount of in vitro transported insulin.

\section{Analysis of blood insulin level}

The method used to determine insulin levels in serum is Sandwich ELISA. Color intensity after the addition of TMB substrate (3, 3', 5, 5'-tetramethylbenzidine) and stop solution measured using ELISA reader at the wavelength of $450 \mathrm{~nm}$. Before use, ELISA kit was verified to know its linearity, accuracy, precision, and suitability with the internal quality controls. The verification results show that the standard curve is linear ( $\mathrm{R} 2=0.9998)$, accurate, precise, and in accordance with internal controls. 
Protein activity depent on the intergrity of three dimensional structure. ELISA results show that SNEEDS are able to preserve biological activity of entrapped Insulin. After oral administration, SNEDDS formulation can increase in AUC, $C$ max, and an $F$ value of insulin (Figure 4). These caused by some factors including lymphatic transport, high surfactant content, and paracellular transport of tight junction (Georgakopoulos et al., 1992). The lipid given orally will be digested and absorbed in intestinal lymphatic. SNEDDS insulin forms nano-sized droplet system that will experience intestinal uptake through lymphoid follicles and Peyer's patches GALT and be transported to spleen either directly or through macrophage phagocytosis effect (Reddy and Murthy, 2002). Insulin also transported to intestinal lymphatic due to its big-sized molecule and resistance to portal circulation absorption (Reddy and Murthy, 2002).

Insulin absorption can be reached using enhancer (Muranishi, 1990) and lipid based vehicles (Porter and Charman, 2001). Long chain lipid will tend to be transported to spleen rather than to portal circulation. The oil used in SNEDDS system is Miglyol $812 \mathrm{~N}$, medium chain triglycerides that will be transported to intestinal lymphatic due to its combination with Tween 80 consisting of oleic acid, long chain fat (C18). Tween 80 is an enhancer that increases the permeability of cell membrane. Tween 80 also has reversible effects in opening tight junction through interaction with polar parts of lipid bilayers (Selvam et al., 2013).

The fastest Cmax reached by Insulin SNEDDS $1 \mathrm{~mL}$ than Insulin SNEDDS $2.5 \mathrm{~mL}$ adn $5 \mathrm{~mL}$ (Figure 4). These can be seen from Insulin SNEDDS given orally as much as $2.5 \mathrm{~mL}$ and $5 \mathrm{~mL}$ reached $\mathrm{Cmax}$ after 240 minutes while Insulin SNEDDS $1 \mathrm{~mL}$ reached Cmax after 45$60 \mathrm{~min}$. These caused by delayed gastric emptying time (Cooke, 1975) and the slow dispersing process of SNEDDS into nanoemulsion in limited gastric media (Porter and Charman, 2001; Pouton, 2000). Fat has a long residence time in the stomach (Cooke, 1975) which delayed gastric emptying time leading to delayed absorption.

Compared with non-SNEDDS insulin, the SNEDDS insulin is absorbed more. This occurs as non-SNEDDS insulin is unstable to
$\mathrm{pH}$ changes of gastrointestinal tract leading to unpredictable speed of insulin absorption. Subcutaneous insulin was used as positive control of blood insulin level. Cmax of this insulin is reached fast, in $15 \mathrm{~min}$, with $4.21 \pm 0.57 \mathrm{ng} / \mathrm{mL}$ of level. The Cmax of SNEDDS insulin of the highest dosage remains smaller than of subcutaneous insulin; this occurs due to bigger insulin hindrance to enter blood through oral route. The protein given subcutaneously will move slowly from tissues to capillary, and it generally reach the bloodstream through lymphatic vessels; the protein given orally must be resistant to the extreme $\mathrm{pH}$ environment and protease that can destroy protein, and it must be able to penetrate the intestinal epithelial membrane to enter the bloodstream.

The result of Pharmacokinetic test reveals that insulin is better given in SNEDDS preparation than in non-SNEDDS preparation; this explains that it is highly possible to enhance the amount of absorbed insulin using SNEDDS preparation.

\section{CONCLUSION}

The resulted design of SNEDDS templates reveals that the optimal SNEDDS template after being loaded with insulin provides nano-emulsion characteristic resulting in bigger amount of in vitro diffused and in vivo absorbed insulin than of non-SNEDDS insulin. This enables the designed SNEDDS formula to be used in per-oral insulin delivery.

\section{ACKNOWLEDGEMENT}

The writer thanks to Ministry of Research, Technology and Directorate of Higher Education of The Republic Indonesia for the financial aid and Faculty of Pharmacy, Universitas Gadjah Mada for the laboratory support.

\section{REFERENCES}

Almeida AJ., Souto E., 2007. Solid lipid nanoparticles as a drug delivery system for peptides and proteins. Adv. Drug Deliv. Rev., 59: 478-490.

Anton N., Vandamme TF., 2009. The universality of low-energy nanoemulsification. Int. J. Pharm., 377: 142147. 
Basalious EB., Shawky N., Badr-Eldin SM., 2010. SNEDDS containing bioenhancers for improvement of dissolution and oral absorption of lacidipine. I: development and optimization. Int. J. Pharm., 391: 203211.

Chinwong S., Chinwong D., Mangklabruks A., 2012. 'The Effect of Daily Consumption of Virgin Coconut Oil on Plasma Lipoproteins Levels in Healthy Thai Volunteers' Geneva Health Forum. (http://ghf.globalhealthforum.net/2012 /01/06/the-effect-of-daily-consumption-of-virgin-coconut-oil-on-plasmalipoproteins-levels-in-healthy-thai-volunteers/\#.U3MY4nYzeeo accessed 14 May 2014).

Cooke AR., 1975. Control of gastric emptying and motility. Gastro-enterology., 68:804-16.

Costa JA., Lucas EF., Queirós YGC., Mansur CRE., 2012. Evaluation of nanoemulsions in the cleaning of polymeric resins. Colloids Surf. $A$ : Physicochem. Eng. Asp., 415: 112-118.

Desmukh A., Kulkarni S., 2014. Solid selfmicroemulsifying drug delivery system of ritonavir. Drug. Dev. Ind .Pharm., 40:47787.

Georgakopoulos E., Farah N., Vergnault G., 1992. Oral anhydrous non-ionic nanoemulsions administered in soft gel capsules. Bulletin Technology Gattefosse., 1119.

Hong JY., Kim JK., Song YK., Park JS., Kim CK., 2006. A new self-emulsifying formulation of itraconazole with improved dissolution and oral absorption. J.Control. Release., 110:332338.

Ittiqo DH., Pramono S., Martien R., 2016, Optimization of the formula SNEDDS purified extract combination of Curcuma xanthorrhiza and Andrographis paniculata (Burm.f.) Nees using Miglyol $812 \mathrm{~N}$ as an oil phase and absorption study in vitro. Thesis, Universitas Gadjah Mada, Indonesia.

Jain S., Kambam S., Thanki K., Jain AK., 2015. Cyclosphorine A loaded selfnanoemulsifying drug delivery system (SNEDDS):implication of a functional excipient based co-encapsulation strategy on oral bioavailability and nephrotoxicity. RSC Adv., 5:49633-42.

Karamanidou T., Karidi K., Bourganis V., Kontonikola K., Kammona O., Kiparissides C., 2015. Effective incorporation of insulin in mucus permeating self-nanoemulsifying drug delivery systems. Eur. J. Pharm. Biopharm., 97(Pt A):223-9.

Kaur G., Harikumar .L., 2013. Formulation Development Of Self Nanoemulsifying Drug Delivery Systems (SNEDDS) Of Celecoxib For Improvement Of Oral Bioavailability. Pharmacophore., 4: 120-133.

Kawakami K., Yoshikawa T., Moroto Y., Kanaoka E., Takahashi K., Nishihara Y., Masuda K., 2002. Microemulsion formulation for enhanced absorption of poorly soluble drugs.I. Prescription design. J. Control. Release., 81:65-74.

Khan AW., Kotta S., Ansari SH., Sharma RK., Ali J., 2015. Self-nanoemulsifying drug delivery system (SNEDDS) of the poorly water-soluble grapefruit flavonoid Naringenin:design, characterization, in vitro and in vivo evaluation. Drug. Deliv., 22(4):552-61.

Khattab A., Hassanin L., Zaki N., 2016. SelfNanoemulsifying drug delivery system of Coenzyme (Q10) with improved dissolution, bioavailability, and protective efficiency on liver fibrosis. AAPSJ, 18:180-6.

Kunasekaran V., Krishnamoorthy K., 2015. Experimental design for the optimization of nanoscale solid lipid particles containing rasagiline mesylate. J.Young. Pharm., 7(4):285-95.

Kurian G., Seetharaman A., Subramanian N., Paddikkala J., 2010. A novel approach for oral delivery of insulin via Desmodium gangeticum Aqueous Root Extract. J. Young Pharm., 2:156-61.

Li P., Tan A., Prestidge CA., Nielsen HM., Müllertz A., 2014. Self-nanoemulsifying drug delivery systems for oral insulin delivery: In vitro and in vivo evaluations of enteric coating and drug loading. Int. J. Pharm., 477: 390-398.

Ma H., Liu Z., Zheng C., 2006. In vitro and in vivo evaluation of a novel oral insulin 
formulation. Acta Pharmacol. Sin,. 27: 1382-1388.

Macedo JPF., Fernandes LL., Formiga FR., Reis MF., Nagashima T., Soares LAL., Egito EST., 2006. Microemultocrit Technique: A valuable tool for determination of critical HLB value of emulsions. AAPS Pharm. Sc. Tech., 7:E1-E7.

Michaelsen MH., Wasan KM., Sivak O., Müllertz A., Rades T., 2016. The Effect of Digestion and Drug Load on Halofantrine Absorption from Selfnanoemulsifying Drug Delivery System (SNEDDS). AAPSJ., 15:219-27.

Mishra A., Panola R., Rana AC., 2014. Microemulsions:As drug delivery system. JSIR., 3(4):467-474.

Mudi, DM., Murray K., Hoad CL., Pritchard SE., Garnett MC., Amidon GL., Gowland PA., Spiller RC., Amidon GE., Marciani L., 2014. Quantification of Gastrointestinal liquid volumes and distribution following a $240 \mathrm{~mL}$ dose of water in the fasted state. Mol. Pharm., 11:3039-47.

Muranishi S., 1990. Absorption enhancers. Crit. Rev. Ther. Drug Carrier Syst., 7:1-33.

Nair AB., Al-ghannam AA., Al-Dhubiab BE., Hasan AA., 2017. Mucoadhesive film embedded with Acyclovir loaded biopolymeric nanoparticles:in vitro studies. J. Young. Pharm., 9(1):100-5.

Nasr A., Gardouh A., Ghorab M., 2016. Novel solid self-nanoemulsifying drug delivery system (S-SNEDDS) for oral delivery of olmesartan medoxomil:design, formulation, pharmacokinetic and bioavailability evaluation. Pharmaceutics., 8(20):1-29.

Park K., Kwon IC., Park K., 2011. Oral protein delivery: Current status and future prospect. React. Funct. Polym., 71: 280-287.

Patel H., Santwani P., Patel P., Akshay K., Ranch K., Shah D., 2013. A review on solid selfemulsification - tecniques, dosage forms development and pharmaceutical applications. JBPR., 2(4):52-56.

Porter CJH., Charman WN., 2001. Transport and absorption of drugs via the lymphatic system. Adv. Drug Deliv Rev., 50:1-2.

Pouton CW., 2000. Lipid formulation for oral administration of drugs:non-emulsifying, self-emulsifying and selfmicroemulsifying drug delivery systems. European J. Pahrm. Sci., 11:S93-S98.

Rachmawati H., Rasaputri D., Susilowidodo R., Darijanto S., Sumirtapura Y., 2010. The influence of oils and surfactants on the formation of self-nanoemul sifying drug delivery systems (SNEDDS) containing therapeutic protein. Materials Science and Technology. Institute Teknologi Bandung.digilib.batan.go.id, accessed 12 December 2014).

Rao SVR., Agarwal P., Shao J., 2008. Selfnanoemulsifying drug delivery systems (SNEDDS) for oral delivery of protein drugs. I. Formulation design. Int. J. Pharm., 362: 10-15.

Reddy LH., Murthy RS., 2002. Lympatic transport orally administered drugs. Indian J. Exp. Biol., 40:1097-1109.

Reddy S., Sowjanya N., 2015. Formulation and in vitro characterization of solid selfnanoemulsifying drug delivery system (sSNEDDS) of simvastatin. J. Pharm. Sci. Res., 7:40-48.

Ruan J., Liu J., Zhu D., Gong T., Yang F., Hao X., Zhang Z., 2010. Preparation and evaluation of self-nanoemulsified drug delivery systems (SNEDDSs) of matrine based on drug-phospholipid complex technique. Int. J. Pharm., 386:282-90.

Sadrzadeh N., Glembourtt M., Stevenson C., 2007. Peptide drug delivery strategies for the treatment of diabetes. J. Pharm. Sci., 96:1925-54.

Sadurní N., Solans C., Azemar N., García-Celma M.J., 2005. Studies on the formation of $\mathrm{O} / \mathrm{W}$ nano-emulsions, by low-energy emulsification methods, suitable for pharmaceutical applications. Eur. J. Pharm. Sci: Official Journal of the European Federation for Pharmacentical Sciences., 26: 438-445.

Sakloetsakun D., Dünnhaupt S., Barthelmes J., Perera G., Bernkop-Schnürch A., 2013. Combining two technologies: Multifunctional polymers and selfnanoemulsifying drug delivery system (SNEDDS) for oral insulin administration. Int. J. Biol. Macromol., 61: 363-372. 
Selvam RP., Kulkarni PK., Dixit M., 2013. Preparation and evaluation of selfnanoemulsifying formulation of efavirenz. IJPER., 47:47-54.

Sharma, G., Wilson, K., van der Walle, C.F., Sattar, N., Petrie, J.R., dan Ravi Kumar, M.N.V., 2010. Microemulsions for oral delivery of insulin: Design, development and evaluation in streptozotocin induced diabetic rats. Eur. J. Pharm. Biopharm., 76: 159-169.

Sonaje K., Lin Y., Juang J., Wey S., Chen C., Sung H., 2009. In vivo evaluation of safety and efficacy of self-assembled nanoparticles for oral insulin delivery. Biomaterials., 30:2329-39.

Thomas N., Holm R., Garmer M., Karlsson JJ., Müllertz A., Rades T., 2013. Supersaturated self-nanoemulsifying drug delivery systems (Super-SNEDDS) enhance the bioavailability of the poorly water-soluble drug simvastatin in dogs. AAPSJ., 15:219-227.

Weerapol Y., Limmatvapirat S., Sriamornsak P., 2014. Self-nanoemulsifying drug delivery system of nifedipine: impact of hydrophilic-lypophilic balance and molecular structure of mixed surfactants. AAPS Pharm. Sci. Tech., 15;435-443.

Winarti L., Suwaldi, Martien R., Hakim L., 2016a. An experimental design of SNEDDS template loaded with bovine serum albumin and optimization using $\mathrm{D}$ optimal. IJPCR., 8:425-432.

Winarti L., Suwaldi, Martien R., Hakim L., 2016b. Formulation of selfnanoemulsifying drug delivery system of bovine serum albumin using HLB (hydrophilic-lypophilic balance) approach. Indonesian J. Pharm., 27:117-127.

Wu W., Niu M., Lu Y., Hovgaard L., 2011. Liposomes containing glycocholate as potential oral insulin delivery systems: preparation, in vitro characterization, and improved protection against enzymatic degradation. Int. J. Nanomedicine., 6:115566.

Zhang Q., He N., Zhang L., Zhu F., Chen Q., Qin Y., Zhang Z., Zhang Q., Wang S., He Q., 2012. The In vitro and In Vivo Study on SNEDDS Based on InsulinPhospholipid Complex. J. Biomed. Nanotechnol., 8:90-7. 